PEIXOTO, N.; BRAZ, L.T.; BANZATTO, D.A.; MORAES, E.A.; MOREIRA, F.M. Características agronômicas, produtividade, qualidade de vagens e divergência genética em feijão-vagem de crescimento indeterminado. Horticultura Brasileira, Brasília, v. 20, n. 3, p.447-451, setembro 2002

\title{
Características agronômicas, produtividade, qualidade de vagens e di- vergência genética em feijão-vagem de crescimento indeterminado
}

\author{
Nei Peixoto'; Leila T. Braz'; David Ariovaldo Banzatto ${ }^{2}$; Ednan A. Moraes ${ }^{1}$; Francisco M. Moreira ${ }^{3}$ \\ ${ }^{1}$ AGENCIARURAL, EEAnápolis, C. Postal 608, 75.001-970, Anápolis-GO, E-mail: upanaps@zaz.com.br. ${ }^{2}$ UNESP, Depto Produção \\ Vegetal, 14.870-000, Jaboticabal-SP; E.mail: leilatb@fcav.unesp.br. ${ }^{3}$ UEG-Ipameri, Anel Viário, 75.800-000 Ipameri-GO.
}

\section{RESUMO}

Avaliou-se a divergência genética entre quinze linhagens (Hav 13, Hav 14, Hav 21, Hav 22, Hav 25, Hav 38, Hav 40, Hav 41, Hav 49, Hav 53, Hav 56, Hav 64, Hav 65, Hav 67 e Hav 68) e cinco cultivares (Macarrão Favorito AG480, Macarrão Preferido AG482, Manteiga Maravilha AG481, Teresópolis AG484 e Macarrão Bragança) de feijão-vagem de crescimento indeterminado, utilizando-se vinte características agronômicas. $\mathrm{O}$ ensaio foi conduzido na AGENCIARURAL - EE de Anápolis, no período de 30/04 a 10/08/ 1998. Os dados foram submetidos às análises de variância e multivariada (distância $\mathrm{D}^{2}$ de Mahalanobis e o método de agrupamento de Tocher). Houve diferenças significativas entre os genótipos para as características consideradas. Os genótipos Hav 13, Hav 49, Hav 56, Hav 64, Hav 68, Favorito AG480 e Teresópolis AG484 destacaram-se com relação ao conjunto de características favoráveis a produtores e consumidores. Houve maior freqüência de pares com maiores distâncias, quando um dos componentes era a cultivar Teresópolis AG484 ou Hav 49, e de pares com menores distâncias quando seus componentes tiveram como ancestral comum a linhagem Hab 229. Os genótipos distribuíram-se em quatro grupos, sendo um constituído exclusivamente pela linhagem Hav 49, outro englobando as cultivares Manteiga Maravilha AG481 e Teresópolis AG484. A linhagem Hav 41 e as cultivares Macarrão Favorito AG480 e Macarrão Preferido AG482 um terceiro grupo, e os demais genótipos um único grupo. As características que mais contribuíram para a divergência entre os genótipos foram o número de dias para o início de floração e o comprimento das vagens, com $58,11 \%$ do total, seguidas da porcentagem de palha na vagem seca, da largura das vagens, das alturas das plantas nas duas épocas avaliadas, do peso médio de vagem e do número de vagens por planta que, em conjunto, contribuíram com $85,73 \%$ do total.

Palavras-chave: Phaseolus vulgaris, ciclo, floração, vigor, vagens verdes, sementes.

\section{ABSTRACT}

Agronomic characteristics, yield, pod quality and genetic divergence in pole beans

Genetic divergence among fifteen breeding lines (Hav 13, Hav 14, Hav 21, Hav 22, Hav 25, Hav 38, Hav 40, Hav 41, Hav 49, Hav 53, Hav 56, Hav 64, Hav 65, Hav 67 and Hav 68) and five cultivars (Macarrão Favorito AG480, Macarrão Preferido AG482, Manteiga Maravilha AG481, Teresopolis AG484 and Macarrão Bragança) of pole beans was evaluated by 20 agronomic characteristics. The field trial was carried out at Anapolis Experiment Station, State of Goias (Brazil), from April 30 to August 10, 1998. The data obtained were submitted to analysis of variance and to the multivariate analysis ( $\mathrm{D}^{2}$ distance of Mahalanobis and grouping method of Tocher). There were statistical differences among genotypes for all studied characteristics. Hav 13, Hav 49, Hav 56, Hav 64, Hav 68, Macarrão Favorito AG480 and Teresopolis AG484 ranked best when the whole characteristics suitable to growers and consumers were considered. There were higher frequency of pairs with the highest distances, when Teresopolis AG484 or the breeding line Hav 49 were a member. The pairs with the lowest distance were those ones with the breeding line Hab 229 as common ancestor. The genotypes were classified into four groups, one with the inbred line Hav 49, a second with Manteiga Maravilha AG481 and Teresopolis AG 484. The inbred line Hav 41 and the cultivars Macarrão Favorito AG480 and Macarrão Preferido AG482 formed a third group. The remaining genotypes formed a single group. The characteristic time from sowing to beginning of blooming and pod length, with $58.11 \%$ of the contribution, followed by percentage of straw in the dry pod, pod width, plant height, pod weight and number of pod per plant. These characteristics were the most effective to genotypes divergence, reaching $85.73 \%$ of the total contribution.

Keywords: Phaseolus vulgaris, cycle, flowering, vigor, green pods, seeds.

(Recebido para publicação em 04 de outubro de 2000 e aceito em 15 de fevereiro de 2002)

$\mathrm{N}^{\mathrm{i}}$ início de um programa de mehoramento de qualquer espécie é desejável que se conheça, além da herança dos caracteres envolvidos, a base genética dos progenitores a serem utilizados (Falconer, 1981). O estudo da divergência genética poderá orientar cruzamentos que possam resultar em combinações híbridas de maior heterozigose, de forma que nas gerações segregantes haja maior possibilidade de recuperação de genótipos superiores (Hanson 1959a,b; Maluf \& Ferreira, 1983; Miranda et al., 1988; Oliveira, 1989; Oliveira et al., 1999).

Na previsão da divergência genética, diferentes métodos multivariados podem ser aplicados, como a análise por componentes principais, por variáveis canônicas e por métodos aglomerativos. Quando o objetivo é identificar progenitores para hibridação, a distância Euclidiana média e, sobretudo a distância generalizada de Mahalanobis são utilizadas rotineiramen- te (Manly, 1986; Braz, 1992; Cruz \& Regazzi, 1997). Em Phaseolus vulgaris L. encontram-se estudos principalmente com feijão comum (Oliveira, 1989; Faria, 1994; Maia, 1996).

Maluf \& Ferreira (1983) estudaram a divergência genética entre dez cultivares de feijão-vagem por meio das técnicas de análise multivariada e observaram baixa correlação entre as distâncias Euclidianas e de Mahalanobis. Entretanto, nos dendogramas oriundos da 
análise de conglomeração, quatro grupos puderam ser constituídos, com os mesmos componentes em ambas metodologias. Por outro lado, Cruz (1997) preconiza alta correlação entre essas medidas.

O presente trabalho teve como objetivo estudar a divergência genética entre 20 genótipos de feijão-vagem de crescimento indeterminado que poderão orientar programas de melhoramento genético com a cultura.

\section{MATERIAL E MÉTODOS}

Estudou-se, na AGENCIARURAL, EE de Anápolis, Goiás, de 30/04 a 10/ 08/1998, a divergência genética entre 20 genótipos de feijão-vagem de crescimento indeterminado, utilizando-se 20 características agronômicas. Os genótipos constituíram-se de quinze linhagens introduzidas do Centro Internacional de Agricultura Tropical (CIAT), sendo dez com o ancestral comum Hab 229 (Hav 13, Hav 14, Hav 38, Hav 40, Hav 41, Hav 56, Hav 64, Hav 65, Hav 67, Hav 68), além de Hav 21, Hav 22, Hav 25, Hav 49, Hav 53 e cinco cultivares brasileiras (Favorito Ag 480, Preferido Ag 482, Manteiga Maravilha Ag 481, Teresópolis Ag 484 e Macarrão Bragança). Localizado em latossolo vermelho-escuro, com cobertura original de cerrado, recebeu adubação de 500 kg/ha da formulação 4$30-16$ no plantio e $200 \mathrm{~kg} / \mathrm{ha}$ de sulfato de amônio, 21 dias após a semeadura.

$\mathrm{O}$ delineamento experimental utilizado foi de blocos casualizados com vinte tratamentos e cinco repetições, sendo as parcelas $\left(4 \mathrm{~m}^{2}\right)$, constituídas de duas fileiras de dez plantas, dispostas no espaçamento de $1,00 \mathrm{~m} \times 0,40 \mathrm{~m}$.

Avaliaram-se as características: 1) Número de flores por inflorescência, obtido pela média de uma inflorescência amostrada na altura média de cinco plantas/parcela; 2) Comprimento (cm) da inflorescência; 3) Vigor das plantas no início do período de colheita (notas de 1 a 3); 4) Altura das plantas (cm) aos 21 dias após a semeadura, medida junto ao suporte, da base até o ápice da planta, desconsiderando-se as tortuosidades; 5) Número de dias da semeadura à antese das primeiras flores $(50 \%$ das plantas da parcela); 6) Altura (cm) das plantas na fase inicial da antese, medida como no item 4 ; 7) Número de nós na rama principal na fase inicial da antese; 8) Produtividade, obtida de oito colheitas, sendo duas por semana, em t/ha de vagens comerciáveis, caracterizadas pelo formato e cor típicos de cada genótipo; 9) Peso médio (g) das vagens comerciáveis, caracterizadas pelo formato e cor típicos de cada genótipo no ponto de colheita; 10) Número de vagens por planta; 11) Comprimento $(\mathrm{cm})$ de vagens no padrão comercial (10 vagens/parcela); 12) Diâmetro de vagens (mm) no padrão comercial (10 vagens/ parcela, tomando-se a medida na sua parte mediana); 13) Largura (mm) de vagens no padrão comercial (10 vagens/ parcela tomando-se a medida na sua parte mediana); 14) Notas (1= ruim a $5=$ excelente) para aspecto visual de vagens comerciáveis colhidas na terceira colheita; 15) Número de vagens por inflorescência amostrada; 16) Número de sementes por vagem nas inflorescências amostradas; 17) Produtividade ( $\mathrm{t} / \mathrm{ha}$ ) de sementes com $13 \%$ de umidade, calculada, segundo BRASIL (1980), de acordo com a fórmula: $\mathrm{F}=$ $\mathrm{I}\left(100-\mathrm{U}_{1}\right) /\left(100-\mathrm{U}_{2}\right)$, onde $\mathrm{F}=$ produção de sementes com a umidade desejada (13\%); I = produção de sementes com a umidade inicial; $\mathrm{U}_{1}=$ umidade inicial das sementes, sendo:

$\mathrm{U}_{1}=(\mathrm{PU}-\mathrm{PF}) * 100 / \mathrm{PU}$ - tara, na qual: $\mathrm{PU}=$ peso de sementes úmidas; $\mathrm{PF}=$ peso de sementes secas; $\mathrm{U}_{2}=$ umidade desejada das sementes $(13 \%)$; 18) Número de sementes por vagem (média de 50 vagens); 19) Porcentagem de casca na vagem seca (média de 50 vagens); 20) Peso (g) de 100 sementes com $13 \%$ de umidade.

Os dados foram submetidos à análise de variância e as médias comparadas pelo teste de Tukey, no nível de 5\% de probabilidade. Para o estudo de divergência entre os genótipos empregaramse como técnica de agrupamento a distância generalizada $\mathrm{D}^{2}$ de Mahalanobis e o método de otimização de Tocher. Determinou-se a contribuição relativa de cada característica para a diversidade pela metodologia de Singh (1981). As análises foram realizadas com recursos do Programa Genes (Cruz, 1997).

\section{RESULTADOS E DISCUSSÃO}

Houve diferenças significativas entre os genótipos para as características avaliadas. Hav 13, Hav 14, Hav 38 e Hav 53 foram as mais precoces, iniciando o florescimento cerca de 15 dias antes de Hav 41 e Macarrão Preferido AG482. A maior nota para vigor foi de Macarrão Favorito AG480 (2,8), que superou os genótipos Hav 22, Hav 56, Hav 65, Macarrão Preferido AG482 e Manteiga Maravilha AG481, todos com nota 2. As linhagens Hav 68 e Hav 64 apresentaram as maiores produtividades, enquanto que Hav 22, Hav 41, Hav 53 , Hav 65 e as cultivares Macarrão Preferido AG482, Manteiga Maravilha AG481 e Macarrão Bragança foram as menos produtivas (Tabela 1).

Plantas de Hav 41 (2,26m) e Macarrão Preferido AG482 (2,32m) tiveram os maiores portes, enquanto que as de Hav $53(1,42 \mathrm{~m})$ foram as mais baixas. Plantas com porte elevado acarretam maior dificuldade de manejo e de colheita. Em geral, a ampliação do ciclo cultural resulta em maior custo de mãode-obra e maior consumo de defensivos, devido à maior ocorrência de pragas $\mathrm{e}$ doenças.

$\mathrm{O}$ número médio de flores por inflorescência variou de 6,0 (Hav 21) a 11,4 (Manteiga Maravilha AG481).

Os genótipos de vagens achatadas produziram vagens mais pesadas, sendo o menor peso médio de Macarrão Bragança $(7,9$ g)e o maior de Teresópolis AG484 (15,9 g). Os maiores comprimentos de vagem foram de Manteiga Maravilha AG481 e Teresópolis AG484, seguidas de Hav 49, todas de vagens achatadas (Tabela 1). Os menores diâmetros de vagens foram de Hav 40 (8,3 mm), inferiores aos de Hav 22 (9,6 mm) e Macarrão Bragança $(9,6 \mathrm{~mm})$. Os dados de largura de vagens seguiram a mesma tendência dos de comprimento. Macarrão Bragança apresentou seção transversal mais cilíndrica. Quanto ao aspecto externo, destacou-se Hav 13, que superou Hav 21, Hav 38 e Hav 40, igualando-se aos demais genótipos (Tabela 1).

A maioria dos consumidores brasileiros prefere cultivares que produzem 
Tabela 1. Número de dias da semeadura à antese das primeiras flores, vigor das plantas no início de colheita, produção de vagens comerciáveis, número de vagens por planta. Anápolis, AGENCIARURAL, 1998.

\begin{tabular}{|c|c|c|c|c|c|c|c|}
\hline Genótipos & $\begin{array}{c}\text { Dias da } \\
\text { semeadura } \\
\text { à antese }\end{array}$ & $\begin{array}{c}\text { Vagens } \\
\text { comerciáveis } \\
\text { (t/ha) }\end{array}$ & $\begin{array}{c}\text { Aspecto } \\
\text { visual das } \\
\text { vagens }^{1 /}\end{array}$ & $\begin{array}{c}\text { Comprim. } \\
\text { vagem }(\mathrm{cm})\end{array}$ & $\begin{array}{l}\text { Produção } \\
\text { de sementes } \\
\text { (t/ha) }\end{array}$ & $\begin{array}{l}\text { Peso de cem } \\
\text { sementes } \\
(\mathrm{g})\end{array}$ & $\begin{array}{c}\mathrm{N}^{\circ} \text { de } \\
\text { sementes/ } \\
\text { vagem }\end{array}$ \\
\hline Hav 13 & $42,0 h$ & $23,25 a b$ & $4,8 a$ & $15,9 \mathrm{de}$ & $3,49 a b c$ & $32,8 \mathrm{ef}$ & 7,0 cdefg \\
\hline Hav 14 & $42,0 \mathrm{~h}$ & $21,78 a b$ & $3,6 a b c$ & $14,5 \mathrm{ef}$ & $3,58 a b c$ & $35,6 \mathrm{cdef}$ & 6,9 cdefgh \\
\hline Hav 21 & $48,0 \mathrm{fg}$ & $19,16 a b c$ & $2,4 \mathrm{c}$ & $14,1 \mathrm{f}$ & $2,55 c$ & $42,7 a$ & $6,0 \mathrm{i}$ \\
\hline Hav 22 & $52,2 \mathrm{~cd}$ & $16,99 \mathrm{bc}$ & $4,0 a b$ & 15,5 ef & $3,13 b c$ & 37,0 bcde & $6,5 \mathrm{ghi}$ \\
\hline Hav 25 & $53,0 \mathrm{bc}$ & $19,01 \mathrm{abc}$ & $3,8 a b c$ & 14,4 ef & $3,61 a b$ & 35,3def & 6,8 defgh \\
\hline Hav 38 & $42,4 h$ & $20,43 a b c$ & $3,2 b c$ & $15,1 \mathrm{ef}$ & $3,31 \mathrm{abc}$ & $32,6 \mathrm{ef}$ & $7,4 \mathrm{bcde}$ \\
\hline Hav 40 & $50,4 d$ & $20,30 a b c$ & $3,2 b c$ & $17,6 \mathrm{~cd}$ & $3,53 a b c$ & $34,4 \mathrm{def}$ & $7,7 \mathrm{bc}$ \\
\hline Hav 41 & $57,8 a$ & $17,54 \mathrm{bc}$ & $4,2 a b$ & $18,0 \mathrm{c}$ & $3,25 a b c$ & $32,9 \mathrm{ef}$ & $7,6 b c$ \\
\hline Hav 49 & $54,4 b$ & $20,12 a b c$ & $4,4 a b$ & $20,8 b$ & $3,84 a b$ & $38,9 \mathrm{abcd}$ & $8,0 a b$ \\
\hline Hav 53 & $43,2 \mathrm{~h}$ & $18,66 \mathrm{bc}$ & $4,6 a b$ & $15,1 \mathrm{ef}$ & $3,60 a b c$ & $31,2 f$ & $7,2 \mathrm{bcdef}$ \\
\hline Hav 56 & $46,2 \mathrm{~g}$ & $20,06 a b c$ & $4,0 a b$ & 15,0 ef & $3,27 a b c$ & $40,4 a b c$ & $6,4 \mathrm{hi}$ \\
\hline Hav 64 & $51,0 \mathrm{de}$ & $23,74 a b$ & $4,0 a b$ & 14,7 ef & $4,29 a$ & $31,4 f$ & $7,3 \mathrm{bcdef}$ \\
\hline Hav 65 & $46,2 \mathrm{~g}$ & $18,74 b c$ & $4,2 a b$ & $14,1 \mathrm{f}$ & $3,17 b c$ & $31,4 f$ & 6,8defgh \\
\hline Hav 67 & $49,6 \mathrm{ef}$ & $21,50 a b c$ & $3,6 a b c$ & 14,4 ef & $3,77 a b$ & $33,8 \mathrm{ef}$ & 6,8 defgh \\
\hline Hav 68 & $48,0 f g$ & $27,06 a$ & $3,6 a b c$ & $15,6 \mathrm{ef}$ & $3,28 a b c$ & 33,9 ef & $7,2 \mathrm{bcdef}$ \\
\hline $\begin{array}{l}\text { Macarrão Favorito } \\
\text { AG480 }\end{array}$ & $53,8 b c$ & $20,37 a b c$ & $4,4 a b$ & $15,1 \mathrm{ef}$ & $3,75 a b$ & $37,2 \mathrm{bcde}$ & 6,7efghi \\
\hline $\begin{array}{l}\text { Macarrão } \\
\text { Preferido AG482 }\end{array}$ & $57,2 a$ & $16,93 \mathrm{bc}$ & $4,2 a b$ & $17,4 \mathrm{~cd}$ & $2,94 b c$ & $35,5 \mathrm{cdef}$ & $7,6 \mathrm{bcd}$ \\
\hline $\begin{array}{l}\text { Manteiga } \\
\text { Maravilha AG481 }\end{array}$ & $54,4 b$ & $17,59 \mathrm{bc}$ & $4,0 a b$ & $23,0 a$ & $3,14 b c$ & $36,1 \mathrm{cdef}$ & $8,7 a$ \\
\hline Teresópolis AG484 & $53,2 b c$ & $20,37 a b c$ & $4,2 a b$ & $23,3 a$ & $3,29 a b c$ & $41,2 a b$ & $8,6 a$ \\
\hline $\begin{array}{l}\text { Macarrão } \\
\text { Bragança }\end{array}$ & $50,0 \mathrm{e}$ & $13,51 \mathrm{c}$ & $4,4 a b$ & 15,3 ef & $2,87 \mathrm{bc}$ & $32,8 \mathrm{ef}$ & 6,6fghi \\
\hline CV (\%) & 1,61 & 17,85 & 15,94 & 4,47 & 13,52 & 6,09 & 4,59 \\
\hline
\end{tabular}

Médias seguidas da mesma letra, na coluna, não diferem entre si a $5 \%$ de probabilidade pelo teste de Tukey

${ }^{1 /}$ Notas $1=$ ruim; 5 = excelente

vagens cilíndricas (Macarrão), utilizando, com menor freqüência, cultivares de vagens achatadas (Manteiga). Estas são associadas a alto teor de fibras, provavelmente pela semelhança com as vagens do feijão comum, altamente fibrosas o que não é verdadeiro para genótipos avaliados, conforme resultados obtidos em Jaboticabal (Hamasaki et al., 1998).

$\mathrm{O}$ número de sementes por vagem variou de 6,0 (Hav 21) a 8,7 (Manteiga Maravilha AG481), não havendo correspondência direta deste com a produtividade de sementes. Houve correspondência dos genótipos quanto à produtividade de vagens no ponto comercial e de sementes. A porcentagem de casca na vagem seca foi maior na cultivar Macarrão Bragança $(26,3 \%)$, superando as demais cultivares e as linhagens Hav 40,
Hav 41 e Hav 49, sendo que Teresópolis AG484 apresentou o menor valor $(15,9 \%)$. Os genótipos de vagens achatadas e graúdas tiveram as menores porcentagens de casca nas vagens secas. Observou-se que cultivares com maiores porcentagens de casca nas vagens secas são mais indeiscentes, oferecendo maiores dificuldades de trilha por ocasião da colheita de sementes.

As maiores sementes foram produzidas por Hav 21, Hav 49, Hav 56 e Teresópolis AG484, e as menores por Hav 53, Hav 64 e Hav 65. Entre as cultivares, Macarrão Bragança produziu as menores sementes e Teresópolis AG484 as maiores (Tabela 1).

O maior tamanho da semente é uma característica indesejável, visto que tende a conferir à superfície externa da vagem aparência indesejável pelas saliên- cias apresentadas com o seu desenvolvimento, requerendo colheitas de vagens com tamanho abaixo do desejável para o produtor, reduzindo-se, assim, a produtividade. Entretanto, cultivares com sementes graúdas, quando associadas à coloração branca e formato cilíndrico, podem ser utilizadas com dupla finalidade: consumo de vagens comestíveis e de grãos secos.

Constatou-se a existência de considerável divergência genética entre os genótipos. Os quatro pares com maiores distâncias generalizadas de Mahalanobis foram Teresópolis AG484 x Hav 67, Teresópolis AG484 x Hav 22, Teresópolis AG484 x Hav 65 e Hav 49 x Hav 67. Um programa de melhoramento que tomar por base estes cruzamentos, poderá resultar na expressão de heterose na descendência, segundo 
Tabela 2. Medidas de dissimilaridade entre pares de 20 genótipos de feijão-vagem, expressas pela distância generalizada de Mahalanobis $\left(\mathrm{D}^{2}\right)$. Anápolis, AGENCIARURAL, 1998.

\begin{tabular}{|c|c|c|c|c|c|c|c|c|c|c|c|c|c|c|c|c|c|c|c|c|}
\hline $\begin{array}{c}\text { Genóti- } \\
\text { pos }\end{array}$ & 1 & 2 & 3 & 4 & 5 & 6 & 7 & 8 & 9 & 10 & 11 & 12 & 13 & 14 & 15 & 16 & 17 & 18 & 19 & 20 \\
\hline 1 & & 22,9 & 177,0 & 275,5 & 327,9 & 35,1 & 228,8 & 627,2 & 679,2 & 70,0 & 90,0 & 261,8 & 83,8 & 181,9 & 101,3 & 370,5 & 573,6 & 621,1 & 1704,4 & 186,7 \\
\hline 2 & & & 146,0 & 271,4 & 304,6 & 23,2 & 268,3 & 683,9 & 752,8 & 66,3 & 65,6 & 242,0 & 66,1 & 159,8 & 100,4 & 376,9 & 615,1 & 734,7 & 843,3 & 196,3 \\
\hline 3 & & & & 129,7 & 196,7 & 184,7 & 221,3 & 451,5 & 521,6 & 212,6 & 39,3 & 205,5 & 93,7 & 110,3 & 96,0 & 195,1 & 384,1 & 574,3 & 619,2 & 157,8 \\
\hline 4 & & & & & 34,0 & 279,7 & 79,0 & 152,6 & 286,6 & 226,3 & 114,0 & 75,4 & 112,8 & 51,2 & 79,8 & 61,3 & 131,9 & 403,5 & 533,7 & 46,2 \\
\hline 5 & & & & & & 324,2 & 125,8 & 156,8 & 395,1 & | 276,0 & 150,4 & 64,3 & 137,7 & 45,1 & $\begin{array}{r}97,4 \\
\text { I }\end{array}$ & 43,7 & 139,6 & 513,8 & 690,9 & 50,5 \\
\hline 6 & & & & & & & 226,3 & 660,0 & 671,9 & 32,5 & 99,2 & 251,0 & 75,5 & 174,8 & 96,8 & 418,3 & 618,2 & 681,2 & 813,2 & 194,1 \\
\hline 7 & & & & & & & & 152,6 & 201,2 & 197,8 & 177,3 & 121,6 & 146,7 & 103,4 & 77,9 & 143,5 & 150,2 & 240,7 & 370,5 & 79,7 \\
\hline 8 & & & & & & & & & 184,2 & 595,4 & 442,0 & 257,0 & 425,9 & 259,6 & 299,6 & 109,7 & 25,9 & 275,6 & 408,4 & 195,7 \\
\hline 9 & & & & & & & & & & 613,2 & 532,5 & 403,4 & 519,8 & 405,8 & 388,5 & 356,4 & 234,9 & 258,9 & 315,0 & 363,6 \\
\hline 10 & & & & & & & & & & & 116,3 & 205,2 & 63,5 & 160,8 & 93,9 & 388,8 & 579,2 & 680,0 & 842,0 & 168,6 \\
\hline 11 & & & & & & & & & & & & 144,0 & 34,6 & 63,8 & 45,9 & 184,3 & 380,8 & 569,5 & 661,3 & 101,5 \\
\hline 12 & & & & & & & & & & & & & 88,3 & 33,0 & 72,4 & 110,5 & 227,4 & 490,5 & 666,0 & 111,6 \\
\hline 13 & & & & & & & & & & & & & & 41,7 & 28,8 & 193,6 & 381,9 & 585,9 & 718,9 & 89,9 \\
\hline 14 & & & & & & & & & & & & & & & 30,9 & 79,7 & 225,0 & 516,7 & 654,0 & 49,5 \\
\hline 15 & & & & & & & & & & & & & & & & 134,7 & 275,2 & 433,9 & 565,3 & 61,4 \\
\hline 16 & & & & & & & & & & & & & & & & & 78,1 & 419,8 & 528,5 & 89,2 \\
\hline 17 & & & & & & & & & & & & & & & & & & 260,5 & 379,5 & 180,9 \\
\hline 18 & & & & & & & & & & & & & & & & & & & 76,9 & 452,5 \\
\hline 19 & & & & & & & & & & & & & & & & & & & & 615,5 \\
\hline
\end{tabular}

Genótipos: 1= $\operatorname{Hav} 13,2=\operatorname{Hav} 14,3=\operatorname{Hav} 21,4=\operatorname{Hav} 22,5=\operatorname{Hav} 25,6=\operatorname{Hav} 38,7=\operatorname{Hav} 40,8=\operatorname{Hav} 41,9=\operatorname{Hav} 49,10=\operatorname{Hav} 53$, 11= Hav 56, 12= Hav 64, 13=Hav 65, 14= Hav 67, 15= Hav 68, 16= Macarrão Favorito AG480, 17= Macarrão Preferido AG482, 18= Manteiga Maravilha AG481, 19= Teresópolis AG484 e 20= Macarrão Bragança

Arunachalan (1981). Entretanto, segundo Hanson (1959a,b), é recomendável utilizarem-se pelo menos quatro progenitores para aumentar o potencial genético e possibilidades de recombinações. Os quatro pares com menores distâncias foram Hav 40 x Hav 67, Hav 65 x Hav 67, Hav 38 x Macarrão Preferido AG482 e Hav 14 x Hav 56 (Tabela 2).

Houve maior freqüência de pares com maiores distâncias, quando um dos componentes era a cultivar Teresópolis AG484 ou Hav 49, e de pares com menores distâncias quando seus componentes tiveram como ancestral comum a linhagem Hab 229. Isto está de acordo com Hanson (1959a,b), segundo o qual, pares formados por indivíduos aparentados tendem a não apresentar divergência. A pequena distância entre Hav 38, de vagens achatadas e Macarrão Preferido AG482, de vagens cilíndricas não pode ser explicada pela origem geográfica, confirmando afirmações feitas por Moll et al. (1965).

Os genótipos distribuíram-se em quatro grupos (Tabela 3). Hav 49 distanciou-se dos demais genótipos, for-

Tabela 3. Composição dos agrupamentos, obtidos pelo método de Tocher, envolvendo 20 genótipos de feijão-vagem. Anápolis, AGENCIARURAL, 1998.

\begin{tabular}{|c|c|}
\hline Grupo & Genótipos \\
\hline 1 & $\begin{array}{l}\operatorname{Hav} 13, \operatorname{Hav} 14, \operatorname{Hav} 21, \operatorname{Hav} 22, \operatorname{Hav} 25, \operatorname{Hav} 38, \operatorname{Hav} 40, \\
\operatorname{Hav} 56, \operatorname{Hav} 53, \operatorname{Hav} 64, \operatorname{Hav} 65, \operatorname{Hav} 67, \operatorname{Hav} 68 \text { e Macarrão } \\
\text { Bragança }\end{array}$ \\
\hline 2 & $\begin{array}{l}\text { Hav 41, Macarrão Favorito AG480 e Macarrão Preferido } \\
\text { AG482 }\end{array}$ \\
\hline 3 & Manteiga Maravilha AG481 e Teresópolis AG484 \\
\hline 4 & Hav 49 \\
\hline
\end{tabular}

mando um grupo isolado, confirmando os valores relativamente elevados das suas distâncias nos pares de que participou. Portanto, é esperado nível satisfatório de heterose em suas progênies, se combinada com os demais genótipos. A presença de 14 genótipos em um único grupo pode ser explicada, em parte, pela origem dos materiais, exceto Macarrão Bragança. Uma exceção marcante a esse argumento, também, é a linhagem Hav 49, em cuja genealogia não apresenta progenitores comuns aos demais genótipos, como pode ser observado na Tabela 1. Por outro lado, Macar- rão Preferido AG482 derivou-se de Macarrão Favorito AG480 pela incorporação de genes de resistência à ferrugem e à antracnose (Carrijo, 1993), mas não se conhece suas relações genealógicas com Hav 41. Manteiga Maravilha AG481 e Teresópolis AG484, de vagens achatadas, grandes, são padrões de mercado de cultivares deste grupo.

As características que mais contribuíram para a divergência entre os genótipos foram o número de dias para o início de floração $(36,70 \%)$ e comprimento das vagens $(21,41 \%)$, a porcentagem de palha na vagem seca $(6,22 \%)$, 
a largura das vagens $(4,96 \%)$, as alturas das plantas aos 21 dias após a semeadura $(4,65 \%)$ e no período inicial de antese $(4,72 \%)$, o peso médio de vagem $(3,28 \%)$, o número de vagens por planta $(3,22 \%)$, o número de sementes por vagem $(2,99 \%)$, o peso de 100 sementes $(2,15 \%)$ e o número de folhas por planta no período inicial de antese (2,09\%) que, em conjunto, contribuíram com $92,96 \%$ do total.

\section{LITERATURA CITADA}

ARUNACHALAM, V. Genetic distance in plant breeding. Indian Journal of Genetics \& Plant Breeding, New Delhi, v. 41, n. 2, p. 226-236, 1981. BRASIL. Ministério da Agricultura. Regras para análise de sementes. Brasília, DNPV/DISEM, 1980. 188 p.

BRAZ, L.T. Estudo da heterose e da capacidade combinatória, visando produção de frutos e sementes de tomate (Lycopersicon esculentum Mill.) Jaboticabal, FCAV, 1992, 123 p. (Tese doutorado). CARRIJO, I.V. Macarrão Preferido Ag-482: nova cultivar de feijão-vagem resistente à ferrugem e antracnose. Horticultura Brasileira, Brasília, v. 11, n. 1, p. 56, 1993.
CRUZ, C.D. Programa Genes. Aplicativo computacional em genética e estatística. Viçosa: UFV, Imprensa Universitária, 1997. 442 p.

CRUZ, C.D.; REGAZZI, A.J. Modelos biométricos aplicados ao melhoramento genético. Viçosa: UFV, Imprensa Universitária, 1997. 390 p.

FALCONER, D.S. Introduction to quantitative genetics. 2.ed. London: Longman, 1981. 340 p.

FARIA, L.C. Análise multivariada no estudo da divergência genética entre populações de feijão (Phaseolus vulgaris L.) do grupo mulatinho. Goiânia, Escola de Agronomia, UFG, 1994. 80 p. (Tese mestrado).

HAMASAKI, R.I.; BRAZ, L.T.; PURQUERIO L.F.V.; PEIXOTO, N. Comportamento de novas cultivares de feijão-vagem em Jaboticabal-SP. In CONGRESSO BRASILEIRO DE OLERICULTURA, 38., 1998, Petrolina. Resumos... Petrolina: SOB, 1998.

HANSON, W.D. Theoretical distribution of the initial linkage block lengths intact in the gametes of a population intermated for $\mathrm{n}$ generations Genetics, v. 44, p. 839-846, 1959a.

HANSON, W.D. The breakup of initial linkage blocks under selected mating systems. Genetics, v. 44, p. 857-868, 1959 b.

MAIA, M.I.C. Estudo de divergência genética por análise multivariada entre 89 acessos de feijão comum (Phaseolus vulgaris L.). Goiânia, Escola de Agronomia, UFG, 1996. 76 p. (Tese mestrado).
MALUF, W.R.; FERREIRA, P.E. Análise multivariada da divergência genética em feijãovagem (Phaseolus vulgaris L.). Horticultura Brasileira, Brasília, v. 1, n. 2, p. 31-34, 1983.

MANLY, B.F.J. Discriminant function analysis. In:__. Multivariate statistical methods: a primer. London: Chapman and Hall, 1986, p. 87-89.

MIRANDA, J.E.C.; CRUZ, C.D.; COSTA, C.P. Predição do comportamento de híbridos de pimentão (Capsicum annuum L.) pela divergência genética dos progenitores. Revista Brasileira de Genética, Ribeirão Preto, v. 11, n. 4, p. 929-937, 1988.

OLIVEIRA, E.J. Análise multivariada no estudo da divergência genética entre cultivares de feijão (Phaseolus vulgaris L.). Viçosa: UFV, Imprensa Universitária, 1989, 91 p. (Tese mestrado).

OLIVEIRA, V.R.; CASALI, V.W.D.; CRUZ, C.D.; PEREIRA, P.R.G.; BRACCINI, A.L. Avaliação da diversidade genética em pimentão através de análise multivariada. Horticultura Brasileira, Brasília, v. 17, n. 1, p. 19-24, 1999.

SINGH, D. The relative importance of characters affecting genetic divergence. Indian Journal of Genetic and Plant Breeding, New Delhi, v. 41, n. 2, p. 237-245, 1981. 